\title{
Waveform classification of airborne synthetic aperture radar altimeter over Arctic sea ice
}

\author{
M. Zygmuntowska ${ }^{1}$, K. Khvorostovsky ${ }^{1}$, V. Helm ${ }^{2}$, and S. Sandven ${ }^{1}$ \\ ${ }^{1}$ Nansen Environmental and Remote Sensing Center, Bergen, Norway \\ ${ }^{2}$ Alfred Wegener Institute, Bremerhaven, Germany \\ Correspondence to: M. Zygmuntowska (marta.zygmuntowska@nersc.no) \\ Received: 4 February 2013 - Published in The Cryosphere Discuss.: 22 March 2013 \\ Revised: 12 July 2013 - Accepted: 15 July 2013 - Published: 19 August 2013
}

\begin{abstract}
Sea ice thickness is one of the most sensitive variables in the Arctic climate system. In order to quantify changes in sea ice thickness, CryoSat-2 was launched in 2010 carrying a Ku-band radar altimeter (SIRAL) designed to measure sea ice freeboard with a few centimeters accuracy. The instrument uses the synthetic aperture radar technique providing signals with a resolution of about $300 \mathrm{~m}$ along track. In this study, airborne Ku-band radar altimeter data over different sea ice types have been analyzed. A set of parameters has been defined to characterize the differences in strength and width of the returned power waveforms. With a Bayesian-based method, it is possible to classify about $80 \%$ of the waveforms from three parameters: maximum of the returned power waveform, the trailing edge width and pulse peakiness. Furthermore, the maximum of the power waveform can be used to reduce the number of false detections of leads, compared to the widely used pulse peakiness parameter. For the pulse peakiness the false classification rate is $12.6 \%$ while for the power maximum it is reduced to $6.5 \%$. The ability to distinguish between different ice types and leads allows us to improve the freeboard retrieval and the conversion from freeboard into sea ice thickness, where surface type dependent values for the sea ice density and snow load can be used.
\end{abstract}

\section{Introduction}

While Arctic sea ice extent and its changes have been studied widely in the last decades (Kwok, 2002; Comiso et al., 2007; Stroeve et al., 2012), sea ice thickness and its decrease remain one of the least observed variables of the Arc- tic climate system (Laxon et al., 2003; Maslanik et al., 2007; Giles et al., 2008; Kwok and Rothrock, 2009). Ice thickness data are sparse and only available from a few campaigns with upward-looking sonar on submarines and moorings (Rothrock et al., 1999, 2008) or helicopter surveys using electro-magnetic induction (Haas et al., 1997, 2010, 2011; Hendricks et al., 2011). Satellite laser and radar altimeters have provided large-scale coverage of ice thickness data in the Arctic, but the operations were limited to certain periods and regions. ICESat's high-resolution laser altimeter, with a footprint of $70 \mathrm{~m}$, covered the area up to $86^{\circ} \mathrm{N}$, while its temporal coverage was limited to two five-week operation periods per year from 2003 to 2009 (Kwok et al., 2004; Kwok and Untersteiner, 2011). Conventional radar altimeters on board ERS-1/2 and Envisat provided continuous highdensity measurements from 1992 to 2012, but have a relatively coarse resolution, with a footprint of several kilometers, and only cover the polar regions up to $81.6^{\circ} \mathrm{N}$ (Laxon et al., 2003). In 2010 CryoSat- 2 was launched addressing the shortcomings of previous altimeter missions (Wingham et al., 2006; Laxon et al., 2013). CryoSat's payload instrument is the SAR/Interferometric Radar Altimeter (SIRAL), which uses the synthetic aperture radar (SAR) technique to enhance the resolution along track. When operating in SAR mode over sea ice, CryoSat- 2 has a footprint of about $270 \mathrm{~m} \times 1000 \mathrm{~m}$, which is a significant improvement compared to the previous ERS and Envisat altimeters. CryoSat-2 orbits the earth with an inclination of $92^{\circ}$, which enables the measurement of sea ice thickness at high latitudes.

Radar altimeter signals from sea ice have been analyzed in many studies since the 1980s (Dwyer and Godin, 1980; Onstott et al., 1987). Dwyer and Godin (1980) published the 
first analysis of radar altimeter waveform signals over sea ice using data from the GEOS-3 satellite. They found altimeter power waveforms over smooth sea ice to rise to a higher value than over the rough open ocean. Drinkwater (1991) and Ulander (1987) found correlations between radar backscatter in SAR images and radar altimeter echo strength and width. Fedor et al. (1989) observed a reduction of the signal response from flat to ridged sea ice. The strongest return signal has been found to come from leads with calm, open water or thin ice, producing specular echo power waveforms (Fetterer, 1992). Encouraged by these findings, the possibility for sea ice classification based on radar altimeter data alone has been discussed in several studies (Chase and Holyer, 1990; Drinkwater, 1991; Laxon, 1994a). Even though the results were promising, the methods have not been developed any further. The current Envisat algorithm for example only distinguishes between leads and ice floes, and large open water areas are masked out by the use of passive microwave data (Laxon et al., 2003; Giles et al., 2008; Ridout et al., 2012). Leads are most commonly identified by the pulse peakiness parameter - the ratio of signal maximum and accumulated power (Peacock and Laxon, 2004; Giles et al., 2007). Sea ice thickness is calculated using prescribed values for ice density and climatological snow depth (Warren et al., 1999).

All the assumptions used in this algorithm are based on conventional altimeters where the waveform is essentially a step function. Once the power has reached the maximum, it remains there for many delay intervals as the area contributing to the power echo is constant over time (Brown, 1977). For synthetic aperture radar altimeters, the signal decays more rapidly after the peak as the area contributing to the response signal decreases with the square root of time (Raney, 1998). The different sampling techniques, and the resulting different echo shape, suggest that a classification of different sea ice types using only waveform data from synthetic aperture radar altimeters may be possible.

In this paper we present a method to distinguish between first-year ice and multi-year ice based on the shape of the radar echo waveform alone. The data used in the study were obtained by an airborne synthetic aperture radar altimeter, ASIRAS, during pre-launch calibration and validation campaigns for CryoSat-2. Different parameters to describe the returned signal and techniques for classification have been explored. The paper contains the following sections: in Sect. 2 we describe the radar altimeter ASIRAS as well as the validation data sets used. Parametrization of the echo power waveforms is described in Sect. 2.2 and the used classification methods in Sect. 2.3. The distribution of each parameter for different surface types and the resulting classification rates are given in Sect. 3. In Sect. 4 our results are compared to previous findings, and perspectives for further applications are discussed.

\section{Data and methods}

\subsection{Instrument and data campaigns}

To examine the possibilities of surface classification based on radar altimeter data, measurements from ESA's CryoSat calibration and validation experiments CryoVEx 2007 and CryoVEx 2008 have been used. Both airborne operations were coordinated by the National Space Institute, Danish Technical University (DTU Space) and the Alfred Wegener Institute (AWI). In 2007 the campaign took place from April 15 to April 25 while in 2008 it lasted from April 15 until May 8. In this study we mainly use data from the Airborne Synthetic Aperture and Interferometric Radar Altimeter System (ASIRAS). The instrument operates at a center frequency of $13.5 \mathrm{GHz}$ (Ku-band) and features alongtrack resolution enhancement by using the synthetic aperture radar technique like its satellite counterpart SIRAL on board CryoSat-2. ASIRAS operates with an antenna beam pattern of 10 degrees along track and 2.5 degrees across track. The footprint size depends on flight altitude but can be considered to be around $10 \mathrm{~m} \times 50 \mathrm{~m}$ at a flight altitude of $300 \mathrm{~m}$. Synthetic aperture radar processing is used to increase the resolution along track, which results in a sampling resolution of $3 \mathrm{~m}$. The return echo power for each data point is recorded with a vertical resolution of approximately $0.095 \mathrm{~m}$ and sampled in a $24 \mathrm{~m}$ range window, corresponding to 256 bins.

Since CryoSat- 2 was primarily designed to measure trends in perennial sea ice, the main validation campaigns took place north of Greenland and Canada, which is an area known to be mostly covered by this type of ice. Single flights have also been performed in areas covered by first-year ice such as Baffin Bay and around the Svalbard archipelago. Therefore we were able to analyze the returned signal waveform over different surfaces such as leads, first-year ice (FYI) and multi-year ice (MYI) (see Table 1). In the area of acquisition, surface types have been identified on contemporary Envisat ASAR wide-swath images (see Fig. 2). In some of the areas, as in the first-year and multi-year ice cases north of Alert, detailed in situ measurements were also available. The area has also been surveyed by an airborne electromagnetic induction device (EM-Bird), which measures the combined snow and ice thickness. Additionally, data from downwardlooking optical cameras on board the airplanes were available. The combination of these data sets gives an excellent knowledge of the ice conditions and allows for a detailed study of the waveform signal over different surface regimes. More information about the campaigns can be found in technical reports (Helm and Steinhage, 2008; Hvidegaard et al., 2009). An overview of the location of the cases analyzed is given in Fig. 1. Further details of the study areas are provided in Table 1. 
Table 1. Overview of the study areas and numbers of available echo waveforms for each case. We evaluated nine cases: two for leads (L), four for first-year ice (FYI) and three for multi-year ice (MYI), each containing several hundred waveforms. Additional data sets, which have been used for obtaining information about the surface type, are listed in the right column. ASAR indicates that an Envisat ASAR wide-swath image was available.

\begin{tabular}{lllrl}
\hline Cases & Date & Description & No. of echoes & Additional data sets \\
\hline L1 & 27.04 .2008 & Leads northeast of Greenland & 566 & ASAR, photo camera \\
L2 & 01.05 .2008 & Leads north of Alert & 1635 & ASAR, photo camera \\
FYI 1 & 21.04 .2007 & Svalbard Walenbergfjorden, fast ice & 3273 & ASAR \\
FYI 2 & 06.05 .2008 & Baffin Bay & 10755 & ASAR \\
FYI 3 & 01.05 .2008 & Thin, flat, snow-covered ice north of Alert & 5248 & ASAR, in situ, EM-Bird, photo camera \\
FYI 4 & 01.05 .2008 & Validation area north of Alert & 513 & ASAR, photo camera \\
MYI 1 & 27.04 .2008 & Big ice field northeast of Greenland & 7223 & ASAR, photo camera \\
MYI 2 & 01.05 .2008 & Sea ice field north of Alert & 7205 & ASAR, photo camera \\
MYI 3 & 01.05 .2008 & Validation area north of Alert & 796 & ASAR, in situ, EM-Bird, photo camera \\
\hline
\end{tabular}

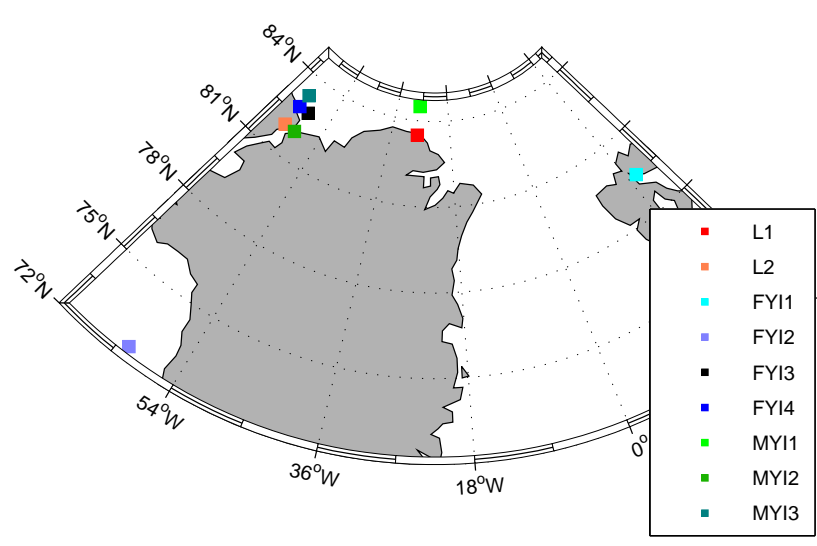

Fig. 1. Map showing the approximate location for each of the evaluated cases (see detailed description in Table 1). Cases with leads (L) are marked in red colors, first-year ice (FYI) in blue and multi-year ice (MYI) in green.

\subsection{Parametrization of waveform shape}

The return signal from the airborne radar altimeter is sampled in a range window of 256 bins, each with a size of about $0.095 \mathrm{~m}$. The signal is usually referred to as power echo waveform or simply waveform. To be able to describe the shape of the waveform quantitatively and account for the differences in strength and width of the signal, the following parameters have been used (see Fig. 3):

- Maximum (Max) value of the power echo.

- Pulse peakiness $(P P)$ is the ratio of the maximum power to the accumulated echo power (first defined by Laxon, 1994b).

$$
\mathrm{PP}=\frac{\max (\text { power })}{\sum_{i=1}^{256} \text { power }(\mathrm{i})}
$$

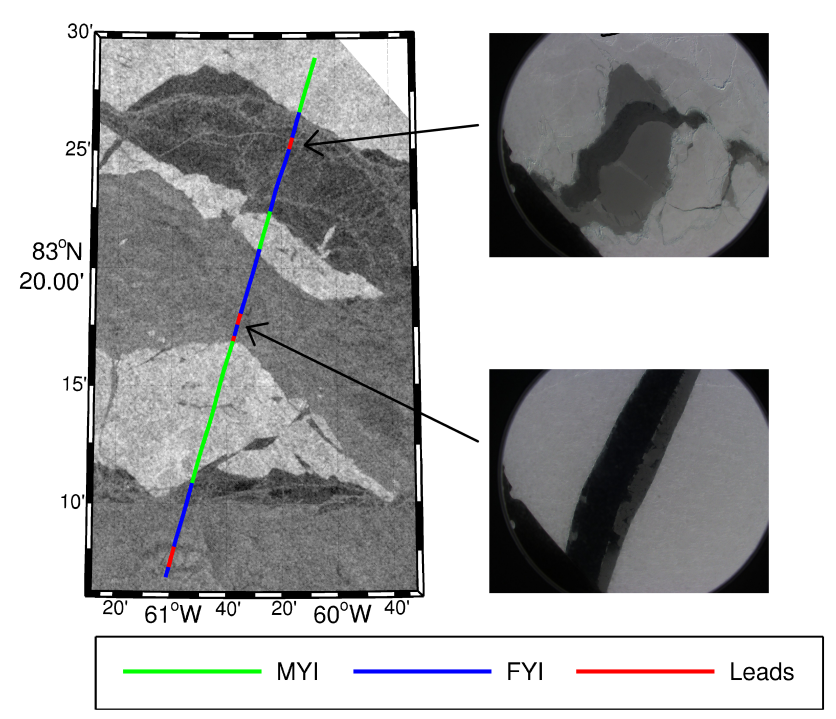

Fig. 2. Example of background information available to retrieve sea ice type north of Alert. Left: Envisat ASAR wide-swath image overlaid with contemporary ASIRAS track from 1 May 2008. In green the ASIRAS track over MYI is shown, in blue FYI and in red the leads. Right: example of camera images used for identifying leads within the ice.

- Leading edge width (LeW) is obtained by fitting a Gaussian curve to the leading edge (starting at the bin containing an echo power larger than $1 \%$ of the power maximum and ending two bins after the bin with the maximum value). The distance between $1 \%$ and $99 \%$ of maximum power echo is defined as the leading edge width (e.g., Legresy et al., 2005).

- Trailing edge width $(\mathrm{TeW})$ is obtained by fitting an exponential decay function to the trailing edge starting with the bin containing the maximum power. The trailing edge width is the distance between the $99 \%$ and $1 \%$ of the power maximum. 


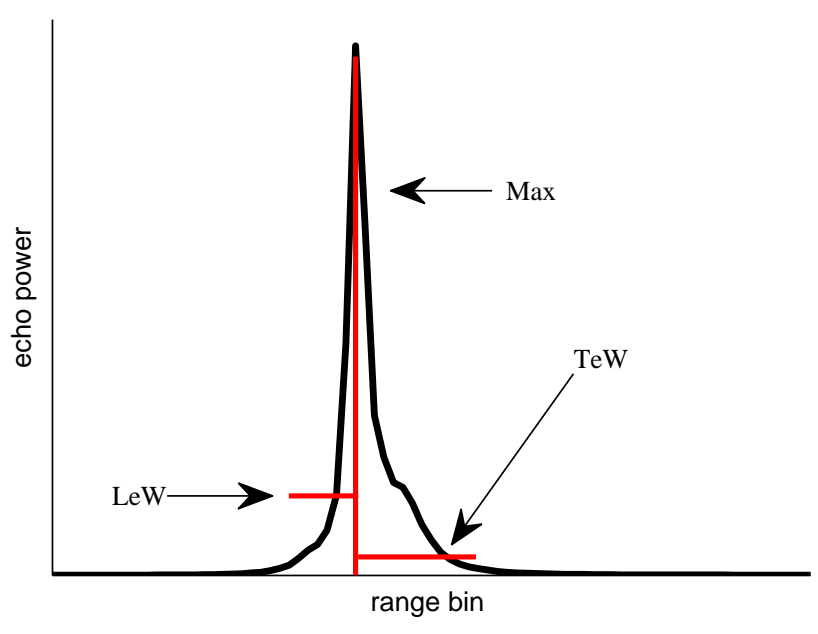

Fig. 3. Subset of the averaged waveform for first-year ice, calculated as the mean of all waveforms retrieved over first-year ice (specified in Table 1). The approximate width of the leading edge and trailing edge are indicated for visualization of these two waveform parameters.

- Trailing edge slope (TeS) is the decay factor for the exponential fit (e.g., Legresy et al., 2005).

\subsection{Classification parameters and methods}

To evaluate which parameters are most distinct for each surface type, and therefore suitable to distinguish between surface classes, the Kolmogorov-Smirnov test (KS test) has been applied. In statistics, the KS test makes it possible to determine if two data sets differ significantly by quantifying the distance between the empirical cumulative distribution functions of two samples. No assumption about the distribution of the two data samples is made, but the test is sensitive to differences in location and shape of the distribution functions.

After analyzing the probability distributions and finding the parameters that are most suitable for classification, two different classification methods have been explored: (1) rulebased threshold method and (2) Bayesian classifier. The threshold method is the one most commonly applied to detect leads within sea ice. The Bayesian classifier is a simple and robust classification method based on supervised learning that formulates the classification problem in probabilistic terms.

\subsubsection{Rule-based threshold}

By analyzing the distribution functions for different surface classes and waveform parameters, it seems straightforward to base a classification on simple thresholds between the classes. This is a widely used method to identify leads, and usually the pulse peakiness parameter or the Maximum are used (Peacock and Laxon, 2004; Giles et al., 2007; Röhrs et al., 2012). We selected an equal number of waveforms from each surface class and set the threshold by maximizing the number of correct classified waveforms from this selection. To minimize the number of false detections, a margin was set around the threshold. The size of the margin equals approximately $2 \%$ of the range of each parameter. Waveforms with classification parameters within this margin are labeled as not classified. The advantages of this rule-based threshold method are that no assumption on the distribution is made and, after setting the threshold, it is very easy to implement.

\subsubsection{Bayesian classifier}

For the classification with the Bayesian approach, our data set has been divided into two different parts: a learning data set with $40 \%$ of all available waveforms and a testing set with $60 \%$. The Bayesian classifier is based on Bayes' theorem (Hanson et al., 1991), which formulates the classification problem in probabilistic terms: based on the probabilities of each surface class and probabilities of the waveform parameters for each class, a probability calculation is used to make a classification decision. The used parameters are PP, Max, $\mathrm{TeW}, \mathrm{TeS}$ and LeW, and the classes are the three surface types, FYI, MYI and leads. In our study we used Gaussian kernel density estimates to model the parameter densities for each class. It is assumed that parameters are conditionally independent and their class distributions are calculated independently. This is a simplification but as the parameters are partly depending on different surface properties, it is reasonable for our purpose. To reduce the number of wrong classifications, we added the requirement that the probability belonging to one class has to be higher than $70 \%$; otherwise waveforms were labeled as not classified.

\section{Results}

\subsection{Typical waveform}

As a first qualitative analysis we show mean waveforms for different surface types in Fig. 4. To account for the difference in surface elevation, all waveforms have been moved so that their maximum values are located in the same sampling bin. The mean of the maximum echo power resulting from reflection over leads is more than 8 times higher than from those coming from sea ice; and even 4 times higher than the mean maximum coming from flat first-year ice (Fig. 4a). The difference in the maximum from the waveforms coming from first-year ice and multi-year ice is less distinct. In Fig. 4b normalized waveforms are shown in order to visualize the difference in the width of the power echo.

Based on the visual analysis of the waveforms, there is a clear difference in the decay after the peak, with multi-year ice having a lower decay rate and a wider trailing edge than 

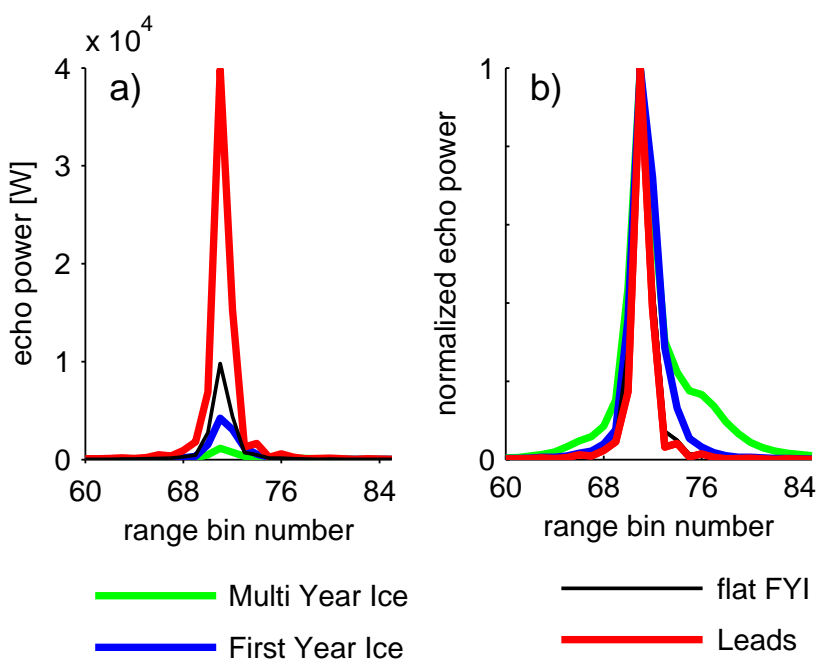

Fig. 4. Averaged waveforms for the three evaluated surface types: leads (red), FYI (blue) and MYI (green). Additionally the mean waveform over flat FYI is shown (black). The waveforms have been calculated as a mean of all available measurements for these surface type as listed in Table 1. (a) Mean reflected waveform for each surface type. (b) Normalized mean waveform to show the difference in the width of the reflected signal.

first-year ice and leads. Reflection over flat FYI (black line) does not result in a wider signal than over leads.

\subsection{Distribution of the parameters}

For each of the waveforms for the analyzed cases, we calculated the five parameters PP, Max, TeW, TeS and LeW. The cumulative probability distributions for each parameter and case are shown in Fig. 5. The more separated the distributions are from one surface type to another, the easier it is to classify the surface type.

For all parameters the spread of the distributions coming from FYI is quite large. Since the term first-year ice refers to a wide range of conditions - ranging from undeformed thin ice to ice that has undergone a high rate of deformation - this is in accordance to our expectations.

The spread of the Max parameter for the FYI distributions is very wide and reaches both extremes: distributions are observed with much smaller and higher values than coming from the MYI cases. The two cases of sea ice with the strongest signal are flat new ice (FYI3) and fast ice (FYI1). In all cases the distributions differ substantially from those obtained over leads (L1 and L2).

The distributions for PP coming from MYI and leads closely resemble each other within these classes. The distributions for FYI in turn largely differ from case to case. The PPs resulting from the power echo waveforms of flat thin ice (FYI3) are almost as high as those resulting from the waveform of leads, while all other cases clearly show smaller PP values. On average, reflection from FYI results in higher PP values than from MYI, but the cumulative probability distributions from FYI and MYI largely overlap. For all cases a clear difference between the distributions from MYI and leads can be found.

The distributions of the parameters related to the leading and trailing edge (the TeW, LeW and TeS) look much alike. We find narrow and similar distributions for the two evaluated cases of leads: a wide spread in the distributions for FYI and wide distributions with long tails for the MYI.

However, even though we found a large spread in the distributions for each class and sometimes large overlaps between single cases from different classes, the KS test shows the averaged distributions for each class are significantly different at a $5 \%$ level for each of the five parameters. To find the parameters best suitable for surface classification, we analyzed the difference between the waveform shapes coming from different surface types more quantitatively. We calculated the mean difference in the cumulative probability distributions for each parameter (Table 2). The difference between the distributions is much larger between leads and sea ice (0.72) than between FYI and MYI (0.52), making it much easier to detect leads within the ice than to distinguish between the two sea ice classes. Differences between the parameters are very small, but they might be large enough to increase the rate of correct classification.

The largest difference between leads and sea ice can be found for the distribution of the Max and the LeW and TeW. Since flat ice is the biggest challenge for the lead detection - flat ice results in a waveform similar to that obtained over leads - we analyzed the difference in the distributions from leads and flat first-year ice (FYI3) more closely (right column in Table 2). We found the larger difference for the Max and TeW and selected these two parameters for lead detection within the ice. Together with the Max and the TeW, we found the TeS to be an adequate parameter to distinguish between MYI and FYI (Table 2). However, as the TeW and TeS are highly correlated, the TeS has been excluded from further analysis.

\subsection{Detection of surface types}

Results from the two classification methods based on PP, Max and TeW are shown in Table 3. A simple threshold method based on PP is the approach used in the Envisat processing chain (Ridout et al., 2012). Therefore, PP has been included in the analysis for comparison. In Table 3 we do not show all possible parameter combinations but present only those leading to the best classification rates. Our classification rates are calculated as described in the following paragraphs.

The rates of correct classification for the different surface classes are the percentage of the waveforms coming from one class that have been correctly classified:

correct classification $_{\text {class } 1}=\frac{\#\left(\text { class }_{\text {class } 1} \cap \mathrm{known}_{\text {class } 1}\right)}{\# \mathrm{known}_{\mathrm{class} 1}}$. 

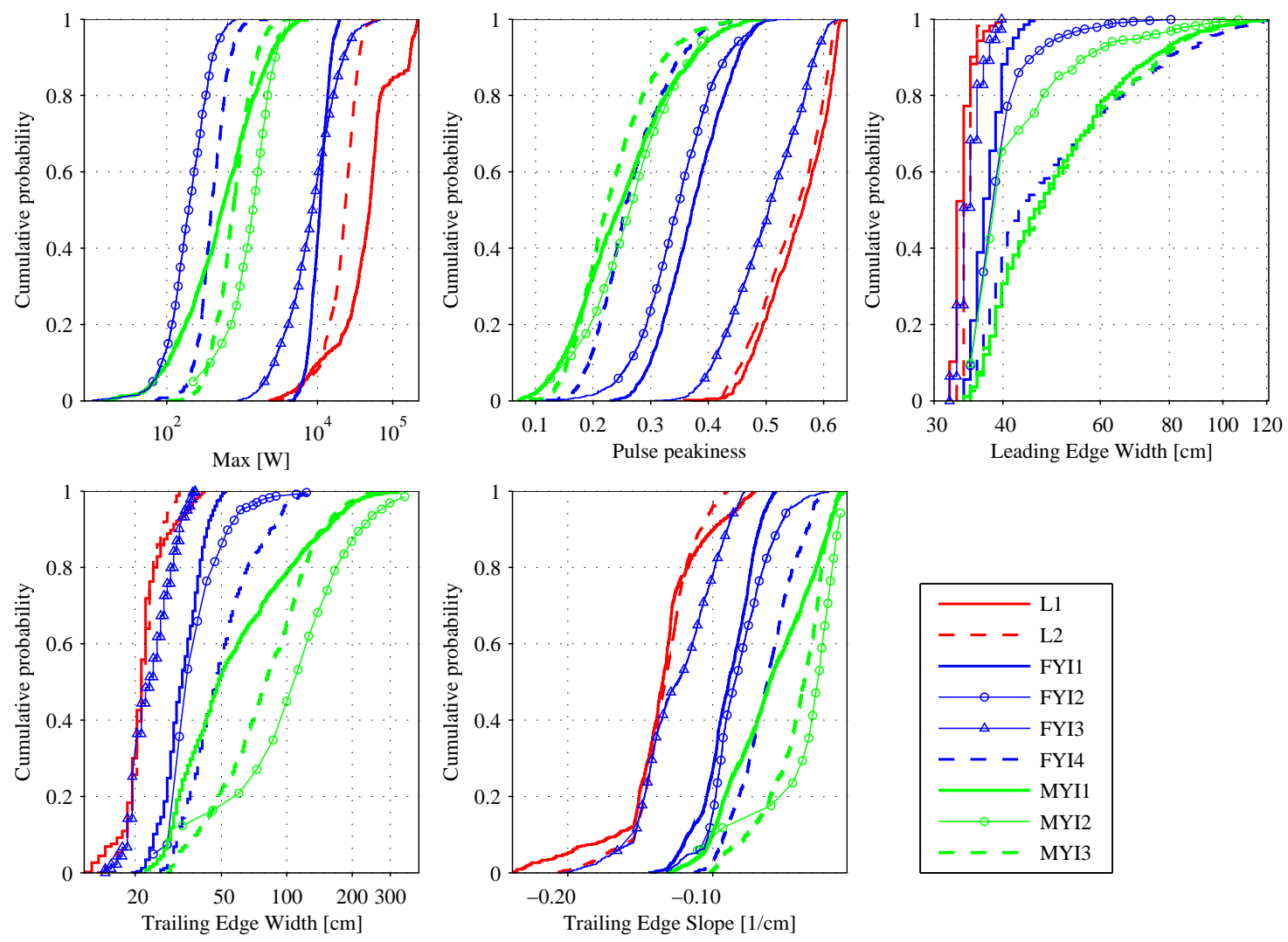

Fig. 5. Cumulative probability distributions for the nine cases (see Table 1) for the five waveform parameters: Max, PP, LeW, TeW and TeS. Distributions obtained from waveforms resulting from leads are shown in red colors, from first-year ice in blue and multi-year ice in green colors.

The rates of false detection are the percentage of waveforms classified as one class while actually belonging to another one:

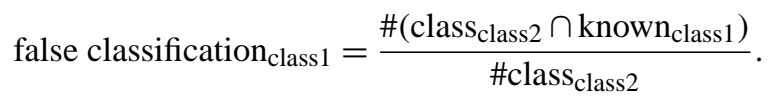

As we selected and divided our waveforms by random choice (for the threshold method we selected an equal number of waveforms of each class, and for the Bayesian approach our data set has been divided into a learning and testing data set), each method has been performed 100 times. The presented classification rates are mean values, and the standard deviation of our results did not exceed $2 \%$.

Almost $95 \%$ of the leads can be identified correctly based on the PP (Table 3). We found a lower average rate of correct classification of $87 \%$ and a detection rate for leads around $83.8 \%$ based on the Max. The percentage of waveforms reflected from sea ice, but falsely classified as a lead, is strongly reduced for the Max parameter (6.5\%) compared to results obtained with the PP (12.6\%). Our Bayesian approach does not significantly increase the detection rate of leads, but does lead to a decrease in false classifications for both leads and
Table 2. Mean distances between the empirical cumulative distribution functions of the five parameters determined from KS test: pulse peakiness (PP), trailing edge slope (TeS), leading edge width (LeW), trailing edge width (TeW), and the power maximum (Max).

\begin{tabular}{lccc}
\hline & $\begin{array}{c}\text { Leads vs. } \\
\text { sea ice }\end{array}$ & $\begin{array}{c}\text { FYI vs. } \\
\text { MYI }\end{array}$ & $\begin{array}{c}\text { Leads vs. } \\
\text { flat FYI }\end{array}$ \\
\hline PP & 0.718 & 0.518 & 0.236 \\
TeS & 0.716 & 0.523 & 0.250 \\
LeW & 0.721 & 0.511 & 0.251 \\
TeW & 0.720 & 0.527 & 0.269 \\
Max & 0.737 & 0.521 & 0.307 \\
\hline
\end{tabular}

sea ice. The advantage of the Bayesian method can also be shown by analyzing the critical case of flat first-year ice (FYI3 in Fig. 5 and Table 1). For the basic threshold method based on the PP parameter, more than $97 \%$ of the waveforms coming from flat ice have been classified as leads, while for the Bayesian approach combining TeW and PP only $87 \%$ are (not shown in the Table).

Results for the two methods for the classification of FYI and MYI are shown in Table 3. Here the use of the Bayesian 
Table 3. Results for the two different classification methods: rule-based threshold and Bayesian classifier. The overall classification rates, the probabilities of correct and false detection for ice and leads (left) and for first-year ice and multi-year ice (right) are presented. The classification rates are defined in Eqs. (2) and (3). The used parameters are the pulse peakiness (PP), the power maximum (Max) and the trailing edge width $(\mathrm{TeW})$.

\begin{tabular}{|c|c|c|c|c|c|c|c|}
\hline \multirow{2}{*}{$\begin{array}{l}\text { Method } \\
\text { Parameter }\end{array}$} & \multicolumn{2}{|c|}{ Threshold } & \multirow{2}{*}{$\begin{array}{c}\text { Bayes' } \\
\text { TeW } \\
\text { and } \\
\text { max }\end{array}$} & \multirow{2}{*}{$\begin{array}{l}\text { Method } \\
\text { Parameter }\end{array}$} & \multirow{2}{*}{$\begin{array}{r}\text { Threshold } \\
\text { PP }\end{array}$} & \multicolumn{2}{|c|}{ Bayes' } \\
\hline & PP & Max & & & & $\begin{array}{l}\text { TeW } \\
\text { and } \\
\text { Max }\end{array}$ & $\begin{array}{r}\mathrm{TeW} \\
\text { and } \\
\mathrm{PP}\end{array}$ \\
\hline \multicolumn{4}{|c|}{ Correct classifications [\%] } & \multicolumn{4}{|c|}{ Correct classifications [\%] } \\
\hline All & 88.0 & 87.3 & 91.3 & all & 72.4 & 80.3 & 79.9 \\
\hline Leads & 94.2 & 83.8 & 94.9 & FYI & 72.6 & 78.7 & 80.5 \\
\hline Ice & 79.5 & 90.8 & 89.1 & MYI & 68.6 & 81.7 & 75.5 \\
\hline \multicolumn{4}{|c|}{ False classifications [\%] } & \multicolumn{4}{|c|}{ False classifications [\%] } \\
\hline Leads & 12.6 & 6.5 & 6.2 & FYI & 26.0 & 10.4 & 23.7 \\
\hline Ice & 5.6 & 12.0 & 2.3 & MYI & 19.2 & 9.1 & 15.7 \\
\hline Not classified & 4.6 & 3.7 & 6.9 & not classified & 6.2 & 11.3 & 12.8 \\
\hline
\end{tabular}

method allows for a strong improvement of the classification by about $8 \%$, resulting in an average detection rate of almost $80 \%$. The rate of false classification can be lowered to about $10 \%$ by using a combination of TeW and Max. The simple threshold method results not only in a poor classification rate but also in a high rate of false classification, where $26 \%$ of the waveforms classified as FYI are actually MYI.

\section{Discussion}

In this study we present a method to distinguish between different sea ice types and leads using airborne $\mathrm{Ku}$-band radar altimeter power waveforms. A method to distinguish between FYI and MYI is presented based on the waveform parameters PP and TeW. With a Bayesian-based method, we were able to classify around $80 \%$ of the waveforms correctly. We can further confirm that a simple threshold method based on the PP parameter is a sufficient method to detect leads. Adding more parameters or using a more advanced method such as the Bayesian classifier does not significantly improve the rate of correct classification. Using Max instead of PP can increase the accuracy in distinguishing leads from undeformed first-year ice, but it also leads to a reduction in the detection rate of leads.

A related analysis was performed by Drinkwater (1991), who analyzed data from a conventional pulse-limited radar altimeter in the marginal ice zone. He found similar results to ours: bare first-year ice results in a high peak value of backscatter and a steep decay; deformed first-year ice results in a lower backscatter and a lower decay gradient; and multi-year ice results in a low peak and a low decay gradient. Despite these findings and even some clustering results that show a clear separation between FYI and MYI, he was skeptical about the possibilities of sea ice classification. In contrast to our study, his analysis was performed in the marginal ice zone where ice floes were smaller than the footprint size. Fedor et al. (1988, 1989) also published sea ice classification results based on conventional airborne radar altimeter waveforms in the Beaufort Sea. They showed that the returned signal decreases from dark nilas over gray ice to more deformed ice types such as rough first-year ice and multi-year ice. Laxon (1994a) presented a method for sea ice classification based on the ERS data by parameterizing the waveform shape, but the method has only been used to distinguish between leads and sea ice. In addition to a qualitative analysis, as done in previous studies, the classification method presented here provides quantitative results. We show that the selected waveform parameters differ significantly for various surface classes and present a method where a combination of waveform parameters leads to a correct classification of $80 \%$ of the waveforms.

Numerous studies have been performed to understand the shape of the radar altimeter waveform and its sensitivity to surface conditions. Laboratory experiments have shown that close to nadir the influence of electrical properties can be neglected (Beaven et al., 1995). The influence of surface roughness has been described by Brown (1977) and Raney (1998). Based on the same laboratory experiments, Beaven et al. (1995) showed that the radar return originates at the snow/ice interface, and snow influence - as long as the snow is dry and cold - can be neglected. Dielectric properties of water have been found to dominate over those of dry snow for volumetric water contents of $1 \%$ (Howell et al., 2005), which can occur at temperatures above $-5^{\circ} \mathrm{C}$ (Garrity, 1992). Based on forward modeling of the reflected radar signal, Makynen and Hallikainen (2009) found that this wet snow cannot be neglected because it alters the waveform shape substantially by adding more volume scattering to the power echo. Willat et al. (2011) confirmed the influence of snow on the radar signal based on data from a dedicated field campaign. The 
influence of surface roughness cannot be separated from the influence of snow properties in the analysis presented. We can only conclude that the combination of difference in ice and snow properties is sufficient to generate a significant difference in the waveform shape.

Therefore more analyses are required to test how our findings can be adapted to satellite-borne altimeter systems. The main difference between the ASIRAS data used in this study and CryoSat-2 data is the resolution. While ASIRAS has a bin width of $9 \mathrm{~cm}$ and a footprint of tens of meters, SIRAL on board CryoSat-2 has a bin width of $45 \mathrm{~cm}$ and a resolution ranging from hundreds to thousands of meters. With this large footprint size, it is more likely that a mixture of different sea ice types occurs within each footprint, which makes a clear separation more difficult. The narrow bin width in the ASIRAS data allows for a detailed record of the returned power. For CryoSat-2 the wide bin width only allows for a detection of large-scale changes in surface structure and signal strength. This further limits the possibility of distinguishing between surface types. A more detailed study is needed to analyze the impact of the different resolutions as well as the influence of snow and roughness on the SIRAL waveform. This has to include measurements from radar and laser altimeters, snow radar, and EM measurements, as well as large-scale information about surface roughness (e.g., ASCAT scatterometer data Andersen et al., 2007) and snow retrievals from passive microwave measurements.

As with any other sea ice classification technique based on remote sensing, the method presented here might be limited to the central Arctic in cold seasons (e.g., Kwok et al., 1992; Zakhvatkina, 2012), where ice types are more distinct and a sufficient area of the radar footprint is covered by ice. The possibility of distinguishing FYI from MYI by radar altimeter data alone is not intended to replace well-established large-scale classification methods based on scatterometer or passive microwave data (Fetterer et al., 1994; Fowler et al., 2004; Andersen et al., 2007; Maslanik et al., 2011). The main benefit of ice classification from radar altimeter data is for improvement of freeboard retrieval and sea ice thickness calculation. Freeboard, the height of the ice above the water level, is retrieved by detecting leads between the ice and finding the difference in elevation of ocean and ice floes. To retrieve the elevation, a re-tracker needs to be applied to determine the position on the leading edge belonging to the surface. For the current Envisat algorithm, different methods are applied for waveforms from sea ice and leads (Ridout et al., 2012). In our study we found the shape of the radar echo waveform to differ significantly between first- and multi-year ice. Therefore we suggest that the identification of different sea ice types can be used to develop a more accurate re-tracker. This could be done by using different fitting procedures to the waveforms depending on surface type. More work is required to test this possibility. The calculation of sea ice thickness from the freeboard measurements is based on the assumption of hydrostatic equilibrium

$h_{\mathrm{i}}=\frac{f_{\mathrm{i}} \rho_{\mathrm{w}}}{\rho_{\mathrm{w}}-\rho_{\mathrm{i}}}+\frac{h_{\mathrm{s}} \rho_{\mathrm{s}}}{\rho_{\mathrm{w}}-\rho_{\mathrm{i}}}$,

where $f_{\mathrm{i}}$ is the ice freeboard, $\rho_{\mathrm{i}}$ the ice density, $\rho_{\mathrm{w}}$ the density of water, $\rho_{\mathrm{s}}$ density of snow and $h_{\mathrm{s}}$ the snow load. The highest uncertainties in sea ice thickness have been found to come from the freeboard retrieval itself, the snow load and from the density of the ice (Forström et al., 2011; Alexandrov et al., 2010). So far snow load has been taken from climatologies (Warren et al., 1999) that are based on measurements on multi-year ice. Recent results from IceBridge laser data over Arctic sea ice reveal a significantly smaller snow load on first-year ice compared to multi-year ice where the snow accumulates over the entire season (Kurtz and Farrell, 2011). Therefore the method presented allows not only the possibility of improving the freeboard retrieval but also using ice type dependent values for the sea ice density and snow load. Previously this has been done by using large-scale sea ice classification retrievals based on scatterometer or passive microwave retrievals. Our method has the benefit of not being dependent on other instruments and providing synchronous information about the surface type. It can improve the sea ice thickness estimates, both on regional and Arctic-wide scales, and improve our knowledge about changes in sea ice thickness.

\section{Conclusions}

In this study, airborne Ku-band radar altimeter data over different sea ice types have been analyzed. It was found that the radar altimeter waveforms retrieved over first-year ice and multi-year ice differ significantly. Various parameters to describe the shape of the radar echo waveforms coming from first-year ice, multi-year ice and leads were evaluated. The maximum of the returned power echo and the trailing edge width were selected as the most suitable ones for sea ice classification. A Bayesian approach used in combination with the waveform parameters was found to be a successful method to distinguish between first-year ice and multi-year ice. With this method it was possible to detect $80 \%$ of the waveforms correctly. In addition, a simple threshold method based on the pulse peakiness parameter was used for lead detection. It was shown that the use of the maximum parameter could lower the rate of false detection of leads. For the pulse peakiness parameter, the false classification rate is $12.6 \%$ while for the power maximum it is reduced to $6.5 \%$. More analyses are required to test the presented method for satellite-based altimeters. The method has the potential to improve the freeboard retrieval by developing a more accurate re-tracker algorithm and improve the conversion of freeboard into sea ice thickness by applying surface-dependent values for sea ice density and snow load. 
Acknowledgements. This work is supported by the Research Council of Norway through the ROMFORSK program (project no. 202313/V30) and ESA PRODEX contract no. 4200090318 CN1. We thank the CryoVEx teams from the Alfred Wegener Institute and the Danish National Space Institute, Danish Technical University (DTU Space), for their work during the campaigns and the data processing. The work from Alfred Wegener Institute was funded by the German Ministry of Economics and Technology (Grant 50EE1008). We gratefully acknowledge the comments from Kjell Kloster and Natalia Ivanova on our manuscript and Laurent Bertino's advice on the statistical methods. The shown SAR image from 1 May 2008 was obtained from the European Space Agency.

Edited by: J. L. Bamber

\section{References}

Alexandrov, V., Sandven, S., Wahlin, J., and Johannessen, O. M.: The relation between sea ice thickness and freeboard in the Arctic, The Cryosphere, 4, 373-380, doi:10.5194/tc-4-373-2010, 2010.

Andersen, S., Breivik, L., Eastwood, S., Godøy, Ø., Lind, M., Porcires, M., and Schyberg, H.: OSI SAF Sea Ice Product Manualv3. 5, EUMETSAT OSI SAF-Ocean and Sea Ice Sattelite Application Facility, Tech. Rep. SAF/OSI/met. no/TEC/MA/125, 2007.

Beaven, S., Lockhart, G., Gogineni, S., Hossetnmostafa, A., Jezek, K., Gow, A., Perovich, D., Fung, A., and Tjuatja, S.: Laboratory measurements of radar backscatter from bare and snowcovered saline ice sheets, Int. J. Remote Sens., 16, 851-876, 1995.

Brown, G.: The average impulse response of a rough surface and its applications, IEEE T. Antenn. Propag., 25, 67-74, 1977.

Chase, J. and Holyer, R.: Estimation of sea ice type and concentration by linear unmixing of Geosat altimeter waveforms, J. Geophys. Res., 95, 18015-18018, 1990.

Comiso, J. C., Parkinson, C. L., Gersten, R., and Stock, L.: Accelerated decline in the Arctic sea ice cover, Geophys. Res. Lett., 34, L01703, doi:10.1029/2007GL031972, 2007.

Drinkwater, M.: Ku band airborne radar altimeter observations of marginal sea ice during the 1984 marginal ice zone experiment, J. Geophys. Res., 96, 4555-4572, 1991.

Drinkwater, M., Francis, R., Ratier, G., and Wingham, D.: The European Space Agency's earth explorer mission CryoSat: measuring variability in the cryosphere, Ann. Glaciol., 39, 313-320, 2004.

Dwyer, R. and Godin, R.: Determining sea-ice boundaries and ice roughness using GEOS-3 altimeter data, 1980.

Fedor, L., Hayne, G., and Walsh, E.: Airborne pulse-limited radar altimeter return waveform characteristics over ice in the Beaufort Sea, in: OCEANS' 88: a Partnership of Marine Interests, Proceedings, 1704-1710, IEEE, 1988.

Fedor, L., Hayne, G., and Walsh, E.: Ice-type Classifications From Airborne Pulse-limited Radar Altimeter Return Waveform Characteristics, in: Geoscience and Remote Sensing Symposium, 1989, IGARSS' 89, 12th Canadian Symposium on Remote Sensing, 1989 International, vol. 3, 1949-1952, IEEE, 1989.
Fetterer, F.: Sea ice altimetry, Tech. rep., DTIC Document, 1992.

Fetterer, F., Gineris, D., and Kwok, R.: Sea ice type maps from Alaska synthetic aperture radar facility imagery: an assessment, J. Geophys. Res., 99, 22-22, 1994.

Forström, S., Gerland, S., and Pedersen, C.: Thickness and density of snow-covered sea ice and hydrostatic equilibrium assumption from in situ measurements in Fram Strait, the Barents Sea and the Svalbard coast, Ann. Glaciol., 52, 261-271, 2011.

Fowler, C., Emery, W., and Maslanik, J.: Satellite-derived evolution of Arctic sea ice age: October 1978 to March 2003, IEEE Geosci. Remote S., 1, 71-74, 2004.

Garrity, C.: Characterization of snow on floating ice and case studies of brightness temperature changes during the onset of melt, Geoph. Monog. Ser., 68, 313-328, 1992.

Giles, K., Laxon, S., Wingham, D., Wallis, D., Krabill, W., Leuschen, C., McAdoo, D., Manizade, S., and Raney, R.: Combined airborne laser and radar altimeter measurements over the Fram Strait in May 2002, Remote Sens. Environ., 111, 182-194, 2007.

Giles, K., Laxon, S., and Ridout, A.: Circumpolar thinning of Arctic sea ice following the 2007 record ice extent minimum, Geophys. Res. Lett., 35, L22502, doi:10.1029/2008GL035710, 2008.

Haas, C., Gerland, S., Eicken, H., and Miller, H.: Comparison of sea-ice thickness measurements under summer and winter conditions in the Arctic using a small electromagnetic induction device, Geophysics, 62, 749-757, 1997.

Haas, C., Hendricks, S., Eicken, H., and Herber, A.: Synoptic airborne thickness surveys reveal state of Arctic sea ice cover, Geophys. Res. Lett., 37, L09501, doi:10.1029/2010GL042652, 2010.

Haas, C., Goff, H., Audrain, S., Perovich, D., and Haapala, J.: Comparison of seasonal sea-ice thickness change in the Transpolar Drift observed by local ice mass-balance observations and floescale EM surveys, Ann. Glaciol., 52, 97-102, 2011.

Hanson, R., Stutz, J. and Cheeseman, P.: Bayesian classification theory, NASA Ames Research Center, Artificial Intelligence Research Branch, 1991.

Helm, V. and Steinhage, D.: CryoVEx 2007-Data Acquisition and Final Processing Report, Tech. rep., 2008.

Hendricks, S., Gerland, S., Smedsrud, L., Haas, C., Pfaffhuber, A., and Nilsen, F.: Sea-ice thickness variability in Storfjorden, Svalbard, Ann. Glaciol., 52, 61-68, 2011.

Howell, S., Yackel, J., De Abreu, R., Geldsetzer, T., and Breneman, C.: On the utility of SeaWinds/QuikSCAT data for the estimation of the thermodynamic state of first-year sea ice, IEEE T. Geosci. Remote, 43, 1338-1350, 2005.

Hvidegaard, S. M., Forsberg, R., Helm, V., Hendricks, S., Skourup, H., Stenseng, L., Hanson, S., and Haas, C.: CryoVEx 2008 Final Report, Tech. rep., Dansh National Space Institute, DTU Space, 2009.

Kurtz, N. and Farrell, S.: Large-scale surveys of snow depth on Arctic sea ice from operation IceBridge, Geophys. Res. Lett., 38, L20505, doi:10.1029/2011GL049216, 2011.

Kwok, R.: The RADARSAT geophysical processor system, 1996.

Kwok, R.: Sea ice concentration estimates from satellite passive microwave radiometry and openings from SAR ice motion, Geophys. Res. Let., 29, 25-1-25-4, 2002.

Kwok, R. and Rothrock, D.: Decline in Arctic sea ice thickness from submarine and ICESat records: 1958-2008, Geophys. Res. Lett., 36, L15501, doi:10.1029/2009GL039035, 2009. 
Kwok, R. and Untersteiner, N.: The thinning of Arctic sea ice, Phys. Today, 64, 36-41, 2011.

Kwok, R., Rignot, E., Holt, B., and Onstott, R.: Identification of sea ice types in spaceborne synthetic aperture radar data, J. Geophys. Res., 97, 2391-2402, 1992.

Kwok, R., Zwally, H., and Yi, D.: ICESat observations of Arctic sea ice: a first look, Geophys. Res. Lett, 31, L16401, doi:10.1029/2004GL020309, 2004.

Laxon, S.: Sea ice altimeter processing scheme at the EODC, Int. J. Remote Sens., 15, 915-924, 1994a.

Laxon, S.: Sea ice extent mapping using the ERS-1 radar altimeter, EARSeL Adv. Remote Sens., 3, 112-116, 1994b.

Laxon, S., Peacock, N., and Smith, D.: High interannual variability of sea ice thickness in the Arctic region, Nature, 425, 947-950, 2003.

Laxon, S. W., Giles, K. A., Ridout, A. L., Wingham, D. J., Willatt, R., Cullen, R., Kwok, R., Schweiger, A., Zhang, J., Haas, C., Hendricks, S., Krishfield, R., Kurtz, N., Farrell, S., and Davidson, M.: CryoSat-2 estimates of Arctic sea ice thickness and volume, Geophys. Res. Lett, 40, 732-737, doi:10.1002/grl.50193, 2013.

Legresy, B., Papa, F., Remy, F., Vinay, G., van den Bosch, M., and Zanife, O.: ENVISAT radar altimeter measurements over continental surfaces and ice caps using the ICE-2 retracking algorithm, Remote Sens. Environ., 95, 150-163, 2005.

Makynen, M. and Hallikainen, M.: Simulation of ASIRAS altimeter echoes for snow-covered first-year sea ice, IEEE Geosci. Remote S., 6, 486-490, 2009.

Maslanik, J., Fowler, C., Stroeve, J., Drobot, S., Zwally, J., Yi, D., and Emery, W.: A younger, thinner Arctic ice cover: Increased potential for rapid, extensive sea-ice loss, Geophys. Res. Lett., 34, L24501, doi:10.1029/2007GL032043, 2007.

Maslanik, J., Stroeve, J., Fowler, C., and Emery, W.: Distribution and trends in Arctic sea ice age through spring 2011, Geophys. Res. Lett., 38, L13502, doi:10.1029/2011GL047735, 2011.

Onstott, R., Grenfell, T., Matzler, C., Luther, C., and Svendsen, E.: Evolution of microwave sea ice signatures during early summer and midsummer in the marginal ice zone, J. Geophys. Res., 92, 6825-6835, 1987.
Peacock, N. and Laxon, S.: Sea surface height determination in the Arctic Ocean from ERS altimetry, J. Geophys. Res, 109, C07001, doi:10.1029/2001JC001026, 2004.

Polyakov, I., Kwok, R., and Walsh, J.: Recent changes of arctic multiyear sea-ice coverage and the likely causes, B. Am. Meteorol. Soc., 92, 145-151, doi:10.1175/BAMS-D-11-00070.1, 2011.

Raney, R.: The delay/Doppler radar altimeter, IEEE T. Geosci. Remote, $36,1578-1588,1998$.

Ridout, A., Ivanova, N., Tonboe, R., Laxon, S., Timms, G., and Kern, S. Kloster, K.: Algorithm Theoretical Basis Document SICCI-ATBDv0-07-12 Version 1.1./03Sept 2012, Tech. rep., ESA, 2012.

Röhrs, J. and Kaleschke, L.: An algorithm to detect sea ice leads by using AMSR-E passive microwave imagery, The Cryosphere, 6 , 343-352, doi:10.5194/tc-6-343-2012, 2012.

Rothrock, D., Yu, Y., and Maykut, G.: Thinning of the Arctic sea-ice cover, Geophys. Res. Lett., 26, 3469-3472, 1999.

Rothrock, D., Percival, D., and Wensnahan, M.: The decline in arctic sea-ice thickness: Separating the spatial, annual, and interannual variability in a quarter century of submarine data, J. Geophys. Res., 113, C05003, doi:10.1029/2007JC004252, 2008.

Stroeve, J., Serreze, M., Holland, M., Kay, J., Malanik, J., and Barrett, A.: The Arctic's rapidly shrinking sea ice cover: a research synthesis, Climatic Change, 110, 1005-1027, 2012.

Ulander, L.: Interpretation of Seasat radar-altimeter data over sea ice using near-simultaneous SAR imagery, Int. J. Remote Sens., 8, 1679-1686, 1987.

Warren, S., Rigor, I., Untersteiner, N., Radionov, V., Bryazgin, N., Aleksandrov, Y., and Colony, R.: Snow depth on Arctic sea ice, J. Climate, 12, 1814-1829, 1999.

Willat, R., Laxon, S., Giles, K.and Cullen, R., Haas, C., and Helm, V.: Ku-band radar penetration into snow cover on Arctic sea ice using airborne data, Ann. Glaciol., 52, 197-205, 2011.

Wingham, D.; Francis, C.; Baker, S.; Bouzinac, C.; Brockley, D.; Cullen, R.; de Chateau-Thierry, P.; Laxon, S.; Mallow, U.; Mavrocordatos, C. and others:CryoSat: A mission to determine the fluctuations in Earth's land and marine ice fields, Adv. Space Res., Elsevier, 37, 841-871, 2006.

Zakhvatkina, N.: Classification of Sea Ice Types in ENVISAT Synthetic Aperture Radar Images, IEEE ASSP Magazine, 2012. 